\title{
ANALISIS NUMERIK EFEK TUMBUKAN DAN POLA DEFORMASI CRASH BOX BERBENTUK ORIGAMI
}

\author{
Romario Fransisco, Sahril Afandi, Bismil Rabeta* \\ Prodi Teknik Penerbangan, Fakultas Teknologi Kedirgantaraan, \\ Universitas Dirgantara Marsekal Suryadarma, Jakarta \\ *Corresponding Author bismilrabeta@yahoo.co.id
}

\begin{abstract}
Abstrak. Crash Box adalah batang longitudinal yang terintegrasi dengan bumper yang digunakan untuk menyerap energi tumbukan akibat tabrakan melalui proses deformasi (progressive buckling). Tujuan dari analisis ini adalah untuk mengetahui respon tabung crash box ketika dikenakan beban tumbukan dengan kecapatan rendah. Selain itu analisis ini juga untuk mengetahui besarnya Pmax (peak force) terhadap variasi geometri yang meghasilkan output berupa nilai gaya terhadap perpindahan, sebagai acuan untuk menentukan nilai dari mean crushing force (Pmean) dan crushing force efficiency (CFE). Pada setiap model memiliki mean crushing force (Pmean) dan crushing force efficiency (CFE) yang berbeda-beda. Pada model 1 memiliki nilai mean crushing force (Pmean) sebesar $12.976 \mathrm{kN}$ dan crushing force efficiency (CFE) sebesar 0.584 , model 2 memiliki nilai mean crushing force (Pmean) sebesar $10.458 \mathrm{kN}$ dan crushing force efficiency (CFE) sebesar 0.789 , dan model 3 memiliki nilai mean crushing force (Pmean) sebesar $9.282 \mathrm{kN}$ dan crushing force efficiency (CFE) sebesar 0.798. Kata Kunci: Crash box, metode elemen hingga, progressive buckling, crushing force efficiency (CFE), deformasi.
\end{abstract}

Abstract. Crash box is a longitudinal bar integrated with a bumper of the car is used to absorp the energy due to collision through a process of deformation (progressive buckling). The purpose of this analyis is to determine the response of the crash box when the subject to collision load with low speed. In addition, this analysis is also to determine the value of Pmax (peak force) against the geometry variations of the crash box that produce the value of the force on the displacement and as a reference to determine the value of mean crushing force (Pmean) and crushing force efficiency (CFE). Every models has a different the value of mean crushing force (Pmean) and crushing force efficiency (CFE). In model 1 has a Pmean value of $12.976 \mathrm{kN}$ and a CFE value of 0.584, Model 2 has a Pmean value of $10.458 \mathrm{kN}$ and a CFE value of 0.789 , and Model 3 has a Pmean value of $9.282 \mathrm{kN}$ and a CFE value of 0.798 .

Keywords : Crash Box, finite element methods, progressive buckling, crushing force efficiency (CFE), deformation.

\section{PENDAHULUAN}

Seiring perkembangan teknologi keamanan pada kendaraan banyak sekali sistem keamanan yang diterapkan oleh produsen kendaraan khususnya roda empat seperti bumper, crash box, airbags, seat belt, dan ABS brakes. Gambar 1 menunjukkan persentase dari tiap jenis tabrakan dimana jenis tabrakan ini sering terjadi karena kepadatan arus lalu lintas yang tinggi. Jenis tabrakan ini terjadi akibat tabrakan dengan mobil lain maupun tabrakan dengan benda-benda lain. ${ }^{[1]}$

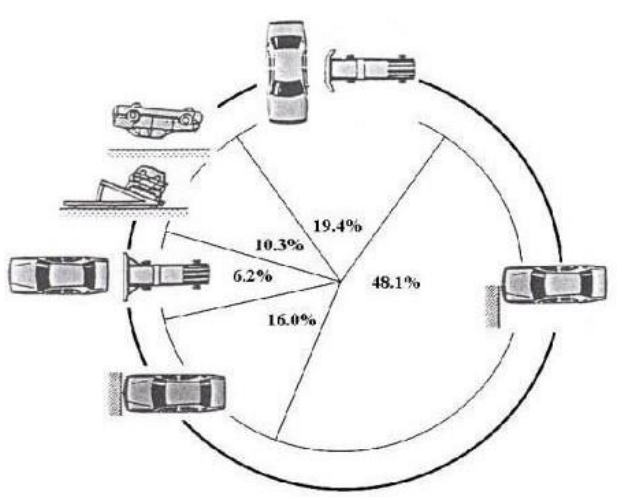

Gambar 1. Distribusi kecelakaan mobil di dunia berdasarkan tipe tabrakan [1] 
Meninjau hal tersebut, standar keselamatan kendaraan yang lebih baik sangat dibutuhkan. Bumper dan crash box berguna untuk melindungi kabin penumpang dari tabrakan arah depan struktur mobil. Desain dan produksi dari sebuah bumper harus dilakukan secara teliti berguna untuk menghasilkan ketahan bumper yang maksimal. Bumper memliki peran penting dampat tabrakan pada mobil. Sistem ini bekerja dengan cara menyerap energi akibat tabrakan dan akan berdeformasi.

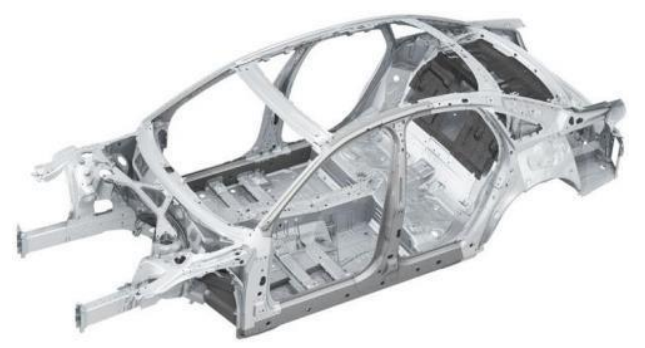

Gambar 2 Struktur bumper dan crushing box[6]
Crash box yang diletakan diantara bumper dan rangka pada bagian depan kendaraan merupakan bagian yang sangat penting sebagai penyerap energi tumbukan menjadi deformasi dari hal tabrakan. Apabila terjadi tumbukan dan crash box tidak terjadi deformasi maka, maka beban tumbukan tersebut akan langsung diteruskan ke dalam daerah kabin, dan penumpang akan langsung merasakan beban tumbukan tersebut. Oleh karena itu, seluruh energi tumbukan harus dapat diserap oleh crash box dan menjadi kerusakan plastis pada crash box tersebut.

\section{METODE PENELITIAN}

\section{Dimensi Pemodelan Geometri}

Pemodelan crash box menggunakan bahan Allumunium 6063-T1 dengan variasi pada jarak antar sudut untuk masing-masing model dari ke 3 model yang dianalisis.

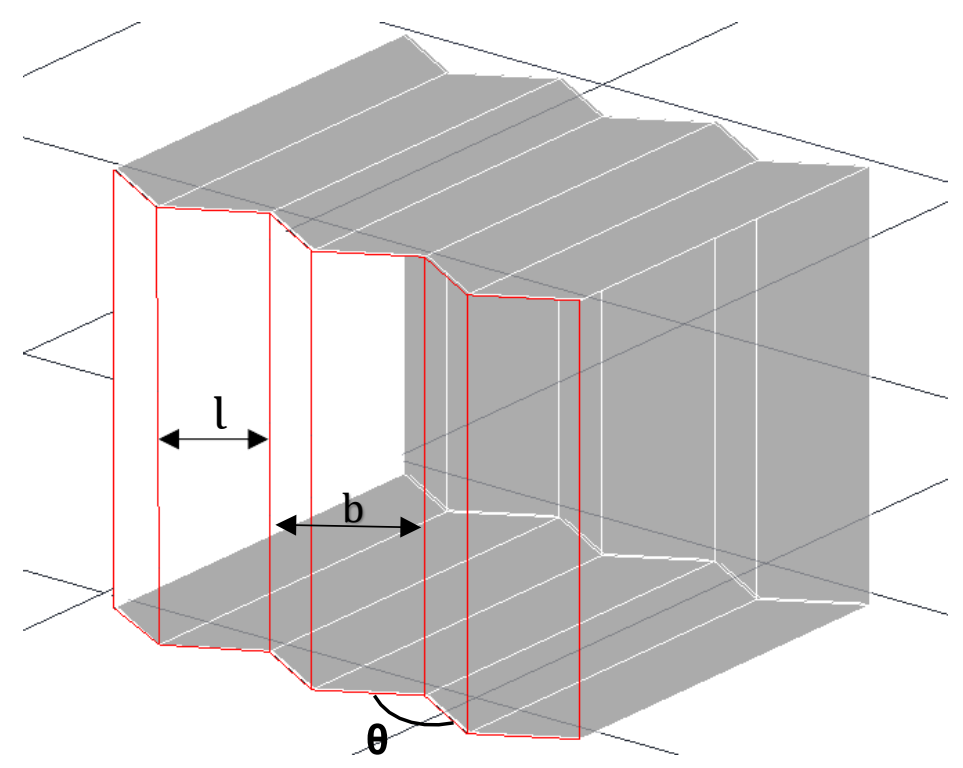

Gambar 3. Penjelasan dimensi pada geometri crash box [11]

Tabel 1. Dimensi geometri crash box

\begin{tabular}{|c|c|c|c|c|c|c|c|}
\hline Model & $(\mathrm{mm})$ & $\left.{ }^{\left({ }^{\circ}\right.}\right)$ & $\mathrm{v}(\mathrm{mm} / \mathrm{s})$ & $\mathrm{b}(\mathrm{mm})$ & $\mathrm{P}(\mathrm{mm})$ & $\mathrm{L}(\mathrm{mm})$ & $\mathrm{H}(\mathrm{mm})$ \\
\hline Ke 1 & 4.177 & 60 & 9800 & 4.177 & 64 & 39 & 100 \\
\hline $\mathrm{Ke} 2$ & 4.177 & 60 & 9800 & 8.355 & 64 & 39 & 100 \\
\hline Ke 3 & 4.177 & 60 & 9800 & 12.533 & 64 & 39 & 100 \\
\hline
\end{tabular}



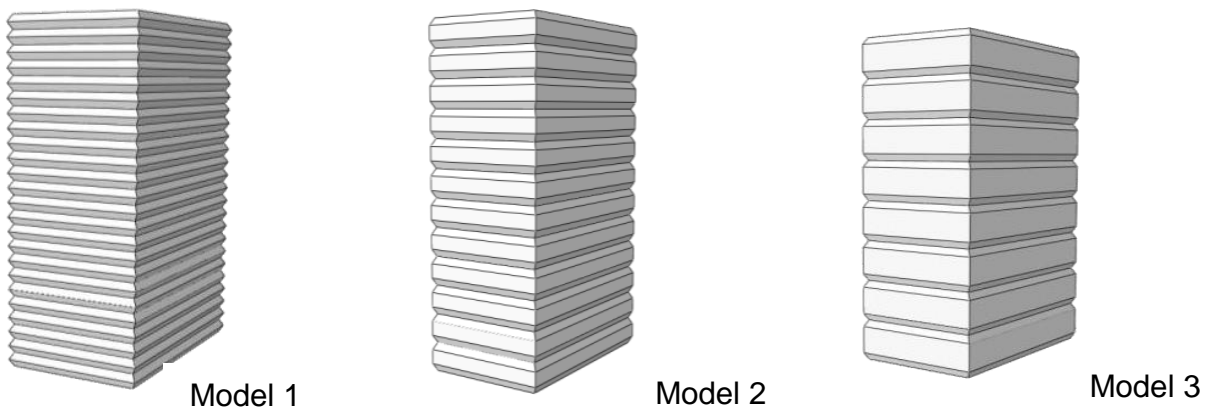

Gambar 4. Model 1, 2, dan 3

\section{Pemodelan}

Pemodelan konstruksi crash box dilakukan dengan menggunakan software berbasis modeling, analysis of mechanical components, assemblies and visualizing the finite element analysis result yaitu abaqus/CAE. Menggunakan material Aluminum 6063-T1, pemilihan ini didasarkan karena kualitas material yang baik dan mudah didapat.

\section{Meshing}

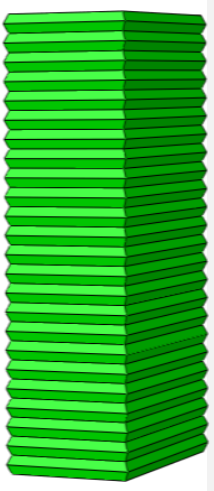

Model 1

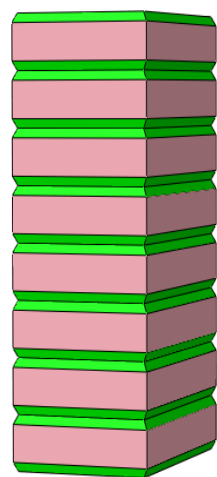

Model 3

Gambar 6. Proses Model Saat Mesh

Proses meshing pada seluruh model dengan jenis element meshing adalah S4R dan jumlah element meshing yang berbedabeda. Meshing dilakukan dalam beberapa tahap yaitu sebagai berikut :

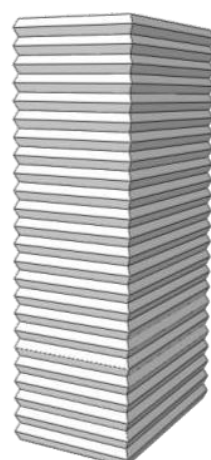

Model 1

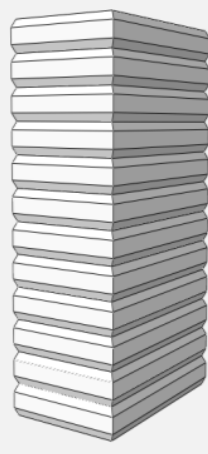

Model 2

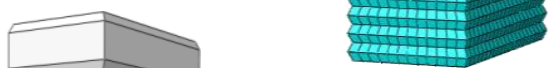

Model 1

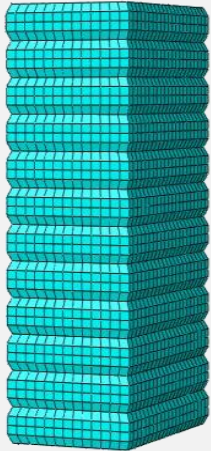

Model 2

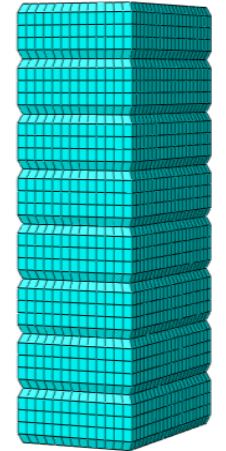

Model 3

\section{Kondisi Pembebanan}

Kondisi ini menjelaskan tentang kecepatan awal impactor (ditunjukkan di bagian top) terhadap objek titik tumbukan predefined fields pada tabung crash box dengan 
kecepatan $9.8 \mathrm{~m} / \mathrm{s}$.

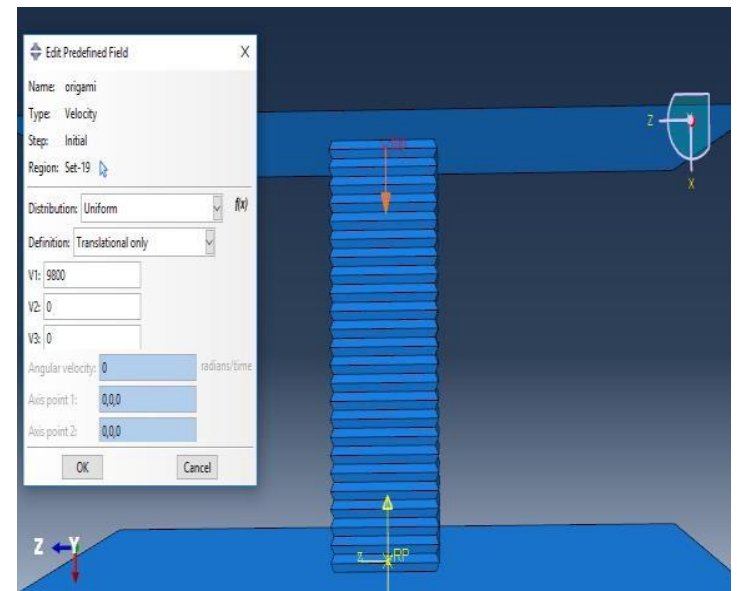

Gambar 8. Menentukan kondisi awal kecepatan impactor

\section{Kondisi Batas}

Kondisi batas (boundary condition) menjelaskan batasan- batasan yang ditentukan oleh penulis pada model tabung crash box. Menentukan batas kondisi letak BC (boundary condition) dengan memilih encastre lalu menandakan bagian tumpu pada bagian bidang tabung crash box bertujuan untuk menentukan letak fix tumpuan material struktur yang menahan deformasi tumpuan tumbukan oleh impactor ersebut. Proses ini juga adalah menentukan komponen yang tetap tak bergerak.

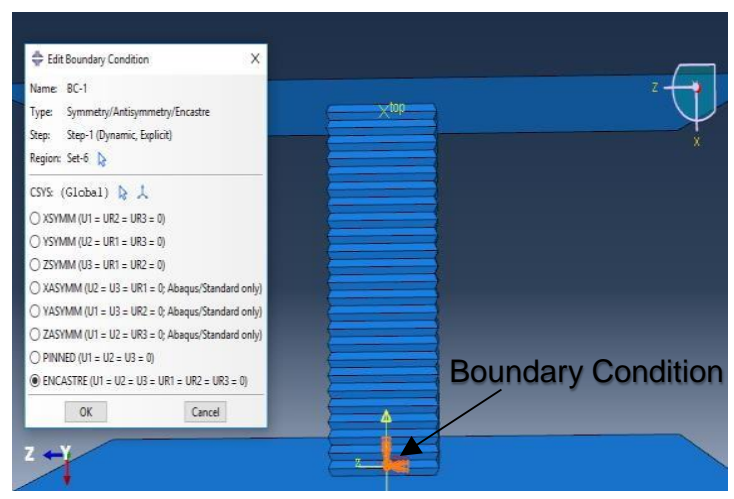

Gambar 9. Menentukan batas kondisi letak BC (boundary condition)

\section{HASIL DAN PEMBAHASAN}

\section{Hasil Analisis}

Pada penelitian ini, simulasi analisis menggunakan 3 model crash box berbentuk origami dengan tujuan untuk mengetahui model paling efisien untuk menerima crushing force akibat tumbukan yang terjadi.

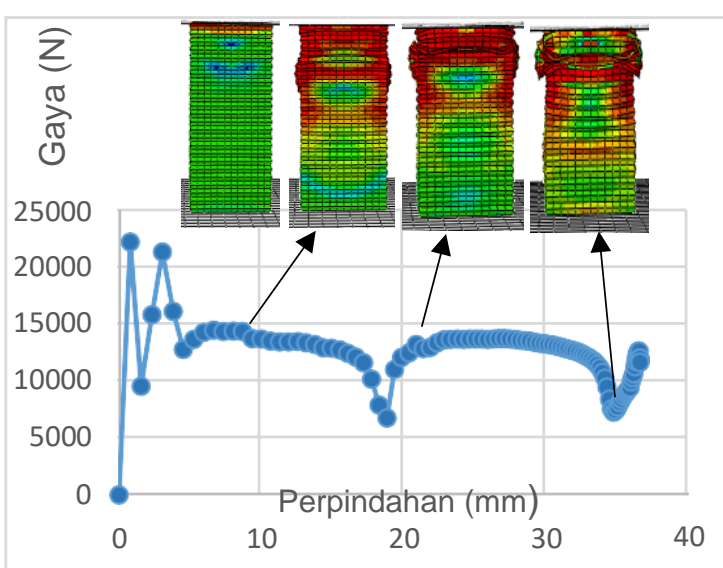

Gambar 10. Mode deformasi dan grafik gaya terhadap perpindahan crash box model 1

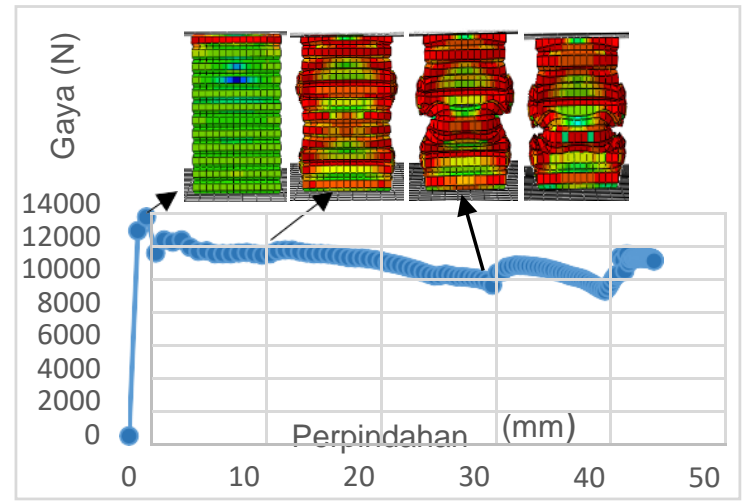

Gambar 11. Mode deformasi dan grafik gaya terhadap perpindahan crash box model 2

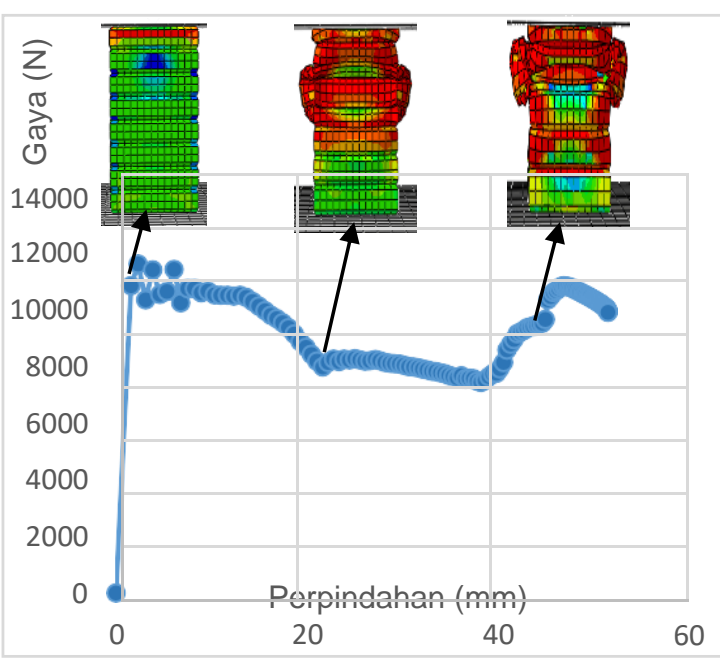

Gambar 12. Mode deformasi dan grafik gaya terhadap perpindahan crash box model 3 


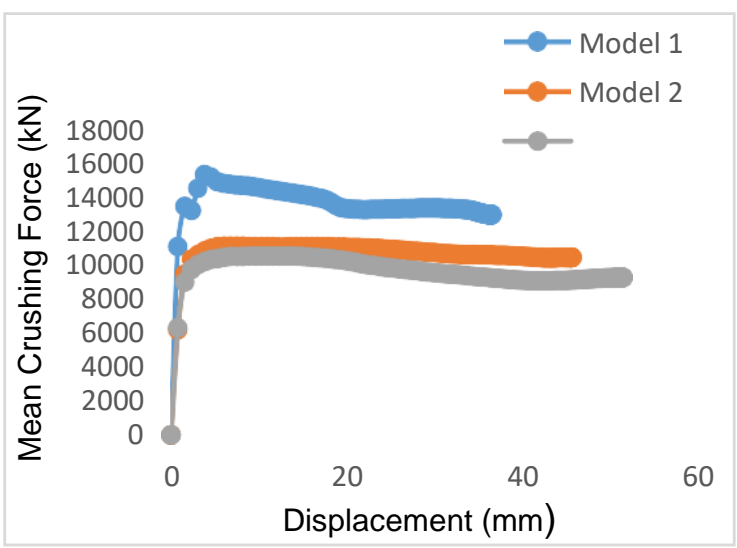

Gambar 13. Perbandingan grafik mean crushing force dari 3 model

Hasil analisis dari ketiga model crash box berbentuk origami ini memiliki pola deformasi lipatan yang berbeda dan nilai Pmax yang berbeda-beda. Pada Model 1 (Gambar 10) memili nilai Pmax sebesar 22.218 kN. Lalu pada Model 2 (Gambar 11) memiliki nilai Pmax sebesar 13.246 kN. Terakhir

pada Model 3 (Gambar 12) memiliki nilai Pmax sebesar 11.619 kN. Dan hasil perhitungan rata-rata dari grafik mean crushing force $(\mathrm{kN})$ untuk model 1 bernilai $12.976 \mathrm{kN}$, untuk model 2 bernilai 10.458 $\mathrm{kN}$, dan untuk model 3 bernilai $9.282 \mathrm{kN}$. Dari hasil analisis numerik pada pemodelan tersebut dapat dilihat perbedannya pada Gambar 10 hingga Gambar 13.

\section{Analisis Numerik}

Pada sub bab ini akan membandingkan hasil pada setiap model yang telah dianalisis untuk mencari perbedaan-perbedaan yang signifikan.

Tabel 3.1 Tabel perbandingan signifikan

\begin{tabular}{|c|l|r|r|}
\hline Indikator & Model 1 & Model 2 & Model 3 \\
\hline $\begin{array}{c}\text { Pmax } \\
(\mathrm{kN})\end{array}$ & 22.218 & 13.246 & 11.619 \\
\hline $\begin{array}{c}\text { Pmean } \\
(\mathrm{kN})\end{array}$ & 12.976 & 10.458 & 9.282 \\
\hline CFE & 0.584 & 0.789 & 0.798 \\
\hline
\end{tabular}

\section{KESIMPULAN}

Pada penelitian ini telah dilakukan uji simulasi dan analisa numerik untuk menentukan model crash box berbentuk origami yang paling efisien dalam menyerap energi saat menerima efek tumbukan. Berdasarkan hasil nilai uji simulasi dan analisa numerik yang telah dilakukan maka didapatkan beberapa hal sebagai berikut :

1. Efek tumbukan pada model pertama hingga ketiga crash box memiliki pola deformasi yang makin banyak dalam hal lipatan,sehingga dapat diurutkan dari model yang memiliki pola lipatan sedikit hingga yang lebih banyak yaitu pertama adalah model 1 , lalu model 2 , dan terakhir adalah model 3. Dimana dengan makin banyaknya pola deformasi dalam hal lipatan menghasilkan nilai Pmax yang makin rendah.

2. Mendapatkan nilai maksimum dari crushing force atau disebut Pmax dari ke 3 model crash box berbentuk origami dengan kecepatan $9.8 \mathrm{~m} / \mathrm{s}$ yaitu nilai Pmax terendah adalah model 3 sebesar $11.619 \mathrm{kN}$.

3. Mendapatkan nilai crushing force efficiency (CFE) terbesar dari ke 3 model crash box yaitu pada model 3 bernilai $79.8 \%$.

Sehingga dapat disimpulkan secara keseluruhan dari 3 faktor diatas bahwa penyerapan energi pada model 3 merupakan penyerapan paling ideal dari ke 3 model crash box.

\section{DAFTAR PUSTAKA}

1. Sitompul, Sahril Afandi, Analisis Numerik dan Eksperimen Tumbukan Kuasi- Statik Pada Tabung Silinder Polyvinyl Chroride, Skripsi Tidak diterbitkan. Fakuktas Teknik Mesin dan Dirgantara, Institut Teknologi Bandung: Bandung. 2011. 
2 David Roylance, Mechanical Properties of Materials. 2008.

http://web. mit.edu/cou

rse/3/3.225/book.pdf,

diakses pada 6 Oktober 2019.

3. Bismil Rabeta, Uji Parametrik Tabung Berpenampang Segi Empat dan Segi enam Terhadap Beban Tumbuk Kecepatan Rendah, Tesis, Fakuktas Teknik Mesin dan Dirgantara, Institut Teknologi Bandung: Bandung. 2011

4. ,2009, http://www.infonum

erik.com/konsep-dasar-finite- elementmethod,

diakses 7 Oktober 2019.

5. Carbodydesign. Audi A8Space Frame http://www.carbodydesig n.com/gallery/2009/12/audi- a8/31/

6. Safety Book, Vehicle Crashworthiness and Occupant Protection, 2004.

7. Tarigopula, V., Langseth, M., Hopperstad, O.S. dan Clausen, A.H., Axial Crushing of Thin-Walled High Strenght Steel Sections, Int. Journal of Impact Engineering 32, pp. 847- 882. 2006
8. Mora, Minda. Low Velocity Impact Analysis of Double- Walled Prismatic Structures Filled With Foam Core, Tesis, Department of Aeronautics and Astronautics Institut Teknologi Bandung : Bandung. 2008

9. Rizkitiawan, Januar. Analisis Numerik Efek Diskontinuitas Tumbukan Kecepatan Rendah Pada Tabung Berpenampang Segienam, Skripsi, Tidak diterbitkan, Fakultas Teknologi Kedirgantaraan Universitas Dirgantara Marsekal Suryadarma. Jakarta. 2018

10. Zhou, C., Wang, B., You, Z., Dynamic Axial Crushing of Origami Crash Boxes, Int. Journal Of Mechanical Sciences 118 Dessault System Simulia Corp, 2014, Abaqus 6.14 User's Guide Simulia Online Documentation. 2016 